proposed modification of the Bachet technique is a safe and reproducible procedure that can avoid the risk of catastrophic bleeding and irreversible cerebral complications even in patients who are candidates for reoperation for large aortic arch aneurysms.

\section{References}

1. Svensson LG, Crawford ES, Hess KR, Coselli JS, Raskin S, Shenaq SA, et al. Deep hypothermia with circulatory arrest. Determinants of stroke and early mortality in 656 patients. J Thorac Cardiovasc Surg. 1993; 106:19-31.

2. Bachet J, Guilmet D, Goudot B, Termignon JL, Teodori G, Dreyfus G, et al. Cold cerebroplegia. A new technique of cerebral protection during operations on the transverse aortic arch. J Thorac Cardiovasc Surg. 1991;102:85-94.

3. Ueda Y, Miki S, Kusuhara K, Okita Y, Tahata T, Yamanaka K. Deep hypothermic systemic circulatory arrest and continuous retrograde cerebral perfusion for surgery of aortic arch aneurysm. Eur J Cardiothorac Surg. 1992;6:36-42.

4. Griepp RB, Juvonen T, Griepp EB, McCollough JN, Ergin MA. Is retrograde cerebral perfusion an effective means of neural support during deep hypothermic circulatory arrest? Ann Thorac Surg. 1997; 64:913-6.

5. Kazui T, Washiyama N, Muhammad BA, Terada H, Yamashita K, Takinami M, et al. Total arch replacement using aortic arch branched grafts with the aid of antegrade selective cerebral perfusion. Ann Thorac Surg. 2000;70:3-9.

\title{
Aortic arch aneurysm with dissection in Cushing syndrome
}

\author{
Hisato Takagi, MD, PhD, Maiko Furukawa, MD, Yukio Umeda, MD, PhD, Yukiomi Fukumoto, MD, PhD, \\ Naomasa Yoshida, MD, Takuya Yamada, MD, PhD, and Yoshio Mori, MD, PhD, Gifu, Japan
}

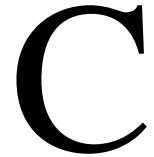

ushing syndrome is caused by glucocorticoid excess and has been known as a risk factor for dissecting aortic aneurysm. To our knowledge, however, only one case of dissecting aortic aneurysm with Cushing syndrome has been found in the English literature. ${ }^{1}$ The authors describe a case of nondissecting true aneurysm of the aortic arch and Stanford type B chronic aortic dissection with Cushing syndrome caused by adrenal cortical adenoma.

A 55-year-old woman, whose moon facies had been pointed out 3 years before, was recently given a diagnosis of Cushing syndrome. Hypertension, glucose intolerance, and proximal muscle weakness were observed. The plasma cortisol concentration was increased to $23.7 \mu \mathrm{g} / \mathrm{dL}(4.0-18.3 \mu \mathrm{g} / \mathrm{dL})$ and was not suppressed by the administration of 1 and $8 \mathrm{mg}$ of dexamethasone. The plasma adrenocorticotropic hormone concentration was less than 5.0 $\mathrm{pg} / \mathrm{mL}$ (7.4-55.7 pg/mL). Computed tomographic scans (Figure 1) disclosed a saccular nondissecting true aneurysm of the distal aortic arch with a mural thrombus, a Stanford type B aortic dissection, and a left adrenal tumor $32 \mathrm{~mm}$ in diameter. There was a history of severe back pain 5 months before, and the dissection was considered to have occurred at that time. The patient simultaneously underwent left adrenalectomy through a laparotomy and graft replacement of the distal aortic arch and the proximal de-

\footnotetext{
From the First Department of Surgery, Gifu University School of Medicine, Gifu, Japan.

Received for publication Aug 11, 2003; accepted for publication Aug 21, 2003.

Address for reprints: Hisato Takagi, MD, PhD, First Department of Surgery, Gifu University School of Medicine, 40 Tsukasa, Gifu 500-8705, Japan (E-mail: h-takagi@cc.gifu-u.ac.jp).

J Thorac Cardiovasc Surg 2004;127:278-9

$0022-5223 / \$ 30.00$

Copyright (C) 2004 by The American Association for Thoracic Surgery

doi:10.1016/j.jtcvs.2003.08.022
}

scending thoracic aorta under partial cardiopulmonary bypass through a left thoracotomy. The dissecting intima was thickened, and therefore the dissection was diagnosed as chronic. Pathologic examination of the adrenal tumor showed cortical adenoma without atypical cells. The elastic fibers of the media was maintained in the dissecting aorta but disrupted in the nondissecting true aortic aneurysm. Although tracheostomy was required postoperatively because of muscle weakness, the patient is doing well 3 months after the operation.

Although Cushing syndrome has been known as a risk factor for dissecting aortic aneurysm, the association of these 2 entities is extremely rare. In 1935, Lawrence and Zimmerman ${ }^{1}$ described a 44-year-old man who presented with the clinical features of Cushing syndrome of pituitary basophilism and died as the result of a ruptured dissecting aortic aneurysm. Although Suzuki and associates $^{2}$ have reported a case of a 31-year-old man who suddenly died of ruptured dissecting aortic aneurysm 5 years after pituitary microsurgical treatment for Cushing disease, the aneurysm might not be directly related to the Cushing disease because of the absence of hormonal abnormalities, including plasma adrenocorticotropic hormone and cortisol levels, for 2 years before the patient's death. The report of Lawrence and Zimmerman ${ }^{1}$ has been the only case of dissecting aortic aneurysm with Cushing syndrome in the English literature. On the other hand, Steffee and Snell ${ }^{3}$ have reported that dissecting aortic aneurysm is produced in hamsters by cortisone acetate. In the media of the aorta adjacent to cortisoneinduced dissecting aneurysm in hamsters, Valigorsky ${ }^{4}$ has demonstrated the occurrence of cellular metaplastic transformation of smooth muscle cells to fibroblast-like cells. It is suggested that hypercortisolemia in Cushing syndrome affects the aortic smooth muscle cells and produces a dissecting aortic aneurysm.

Yoshitomi and colleagues ${ }^{5}$ have presented a 26-year-old woman with splenic artery aneurysm and Cushing syndrome, and it has been speculated that chronic hypercortisolemia caused by the syndrome was causally related to the aneurysm. Although Reilly and associates ${ }^{6}$ have established the role of hydrocortisone in the induc- 

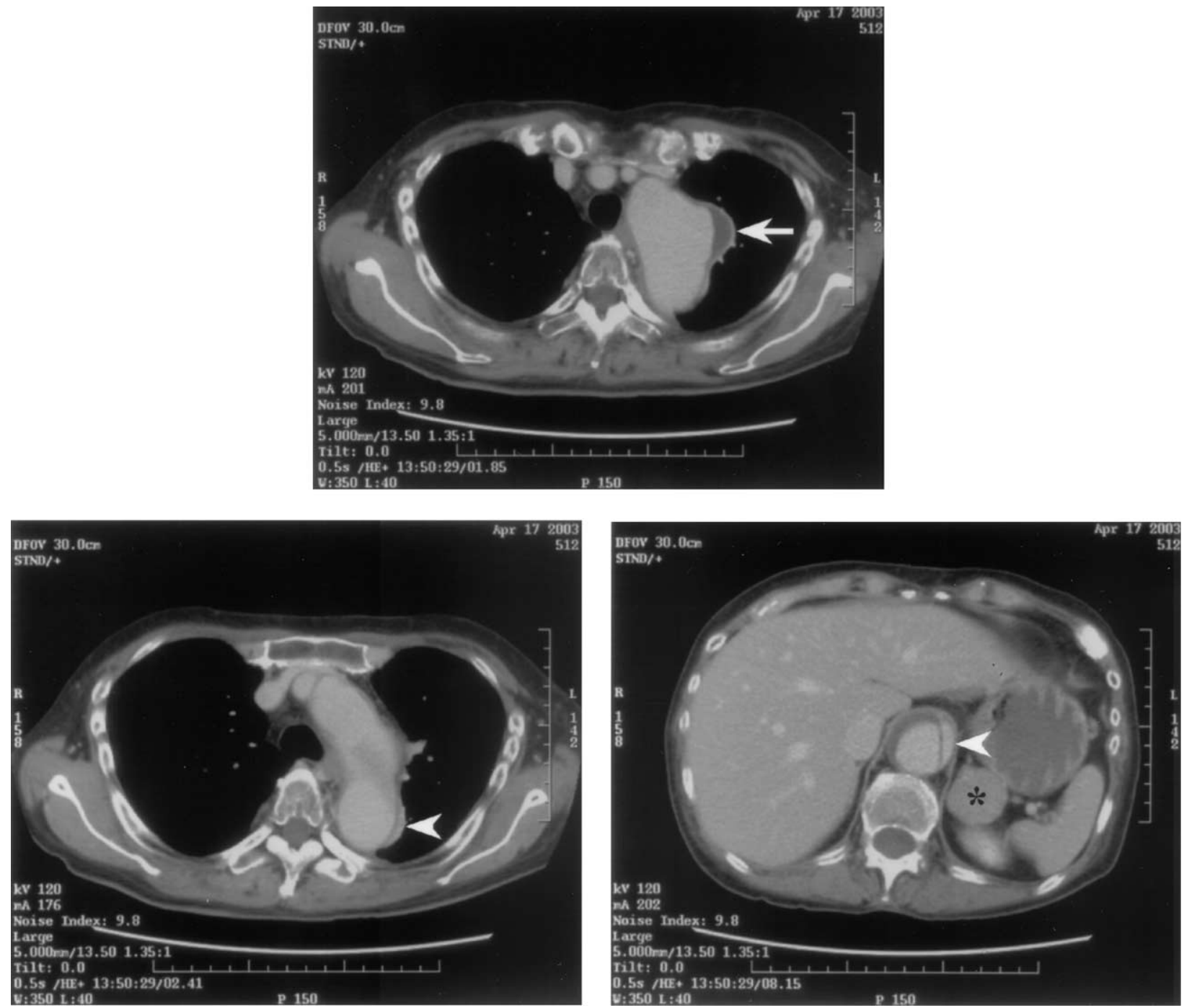

Figure 1. Computed tomographic scans disclosed a saccular nondissecting true aneurysm of the distal aortic arch with a mural thrombus (arrow at top), a Stanford type B aortic dissection (arrowheads at left and right), and a left adrenal tumor $32 \mathrm{~mm}$ in diameter (asterisk at right).

tion of aortic aneurysm and ectasia in mice, any cases of nondissecting true aortic aneurysm with Cushing syndrome have never been found. The present case is not only the second case of dissecting aortic aneurysm in the English literature but also the first case of nondissecting true aortic aneurysm with Cushing syndrome.

In conclusion, a case of nondissecting true aneurysm of the aortic arch and Stanford type B chronic aortic dissection with Cushing syndrome caused by adrenal cortical adenoma was described. The aortic lesions of the present patient with Cushing syndrome suggest that the development of nondissecting true aortic aneurysm, aortic dissection, or both might be related to increased plasma glucocorticoid levels in human subjects, as well as in experimental animals.

We thank Emeritus Professor Dr Kiyoshi Inada, Gifu University, for his advice on the preparation of the article.

\section{References}

1. Lawrence JH, Zimmerman HM. Pituitary basophilism. Report of a case. Arch Intern Med. 1935;55:745-9.

2. Suzuki T, Sasano H, Murakami O, Nagura H. A case of ruptured dissecting aneurysm 5 years after pituitary microsurgical treatment of Cushing's disease: autopsy findings in the hypothalamic-pituitary-adrenal axis. Endocr J. 1993;40:613-8.

3. Steffee $\mathrm{CH}$, Snell KC. Dissecting aortic aneurysm in hamsters treated with cortisone acetate. Proc Soc Exp Biol Med. 1955;90:712-4.

4. Valigorsky JM. Metaplastic transformation of aortic smooth cells in cortisone-induced dissecting aneurysms in hamsters. Fed Proc. 1969; 28:802.

5. Yoshitomi Y, Yoshimi H, Yutani C. A case of splenic artery aneurysm with Cushing's syndrome. Int J Cardiol. 1996;54:263-5.

6. Reilly JM, Savage EB, Brophy CM, Tilson MD. Hydrocortisone rapidly induces aortic rupture in a genetically susceptible mouse. Arch Surg. 1990;125:707-9. 